\title{
三氟甲基自由基促进的烯烃官能团迁移新进展
}

\author{
邱云亮* 魏凤姣叶 滚赵旻玥
}

(南京森林警察学院 刑事科学技术学院 南京 210023)

\begin{abstract}
摘要 引入三氟甲基官能团可以有效地改善功能分子的化学稳定性、代谢稳定性及脂溶性等理化性质. 发展三氟甲基 化合物的高效合成方法具有重要的应用价值. 近年来，三氟甲基自由基与烯烃的反应得到了迅速的发展，其形成的烷 基自由基物种促进分子内官能团的迁移，极大地丰富了烯烃的官能团化方式，在实现烯烃三氟甲基官能团化的同时， 为迅速构建多样性的分子提供了有效的策略, 并推动了有机自由基化学的发展. 根据烯烃类型的不同, 分为官能团化 的烯丙基化合物和非活化烯烃两大部分，对近年来发展的三氟甲基自由基促进的烯烃的双官能团化反应进行了总结. 各部分根据迁移官能团种类不同，详细讨论了不同方式的自由基产生途径、反应的适用范围和局限性以及不同催化体 系的反应机理. 最后, 进一步对基于烯烃三氟甲基化引发的官能团迁移反应进行了总结, 分析了目前的一些研究现状. 关键词 烯烃; 三氟甲基化; 迁移; 双官能团化; 自由基
\end{abstract}

\section{Advances in Trifluoromethylation-Promoted Functional Group Migration of Alkenes}

\author{
Qiu, Yunliang* Wei, Fengjiao Ye, Liu Zhao, Minyue \\ (Department of Criminal Science and Technology, Nanjing Forest Police College, Nanjing 210023)
}

\begin{abstract}
The incorporation of trifluoromethyl functional groups can effectively improve the chemical stability, metabolic stability and liposolubility of functional molecules. Therefore, the development of efficient methods to synthesize trifluoromethyl compounds is of significant importance. In recent years, great progress has been made in the reaction of a trifluoromethyl radical and alkene, in which alkyl radical species was first formed, followed to promote intramolecular functional groups migration. The novel pathways not only provide practical strategy for the functionalization of alkenes, which can realize the rapid construction of diverse molecules, but also promote the development of organic radical chemistry. The recent advances in alkene trifluoromethylation-initiated functional group migration including functionalized allylic compounds and non-activated alkenes are sumarrized. According to different types of migrating functional groups, the reaction in the two different sections are classified, in which the pathways of free radical generation, the scope and limits of the reaction and the reaction mechanism in different catalytic systems are discussed and highlighted in detail. Finally, a perspective on the further development of this research area is made.
\end{abstract}

Keywords alkene; trifluoromethylation; migration; difunctionalization; radical

烯烃是构建有机分子结构最基础的结构单元之一, 不仅广泛存在于许多药物、材料及天然产物等功能分子 中, 也是有机合成和化工产品的重要原料. 自 1959 年 Wacker 氧化反应被发现以来, 烯烃的官能团化反应研 究成为化学工作者关注的热点之一[1]. 特别是烯烃的双 官能团化, 由于其原料廉价易得和转化的多样性也吸引 了越来越多化学家的关注, 成为合成化学研究的热门领 域之一 ${ }^{[2]}$. 其中, 自由基加成策略为烯烃的双官能团化
反应提供了新的有效途径. 产生的自由基首先与双键加 成生成新的碳自由基，随后迁移基团在近端或远端驱动 力的作用下进行迁移，得到烯烃的双官能团化产物(图 1). 通过自由基促进的分子内迁移策略可以原子经济性 地实现简单烯烃向复杂结构的转化, 具有重要的应用价 值.

在功能分子中引入三氟甲基基团可以有效地改善 其理化特性, 如化学稳定性、代谢稳定性和脂溶性等,

\footnotetext{
* Corresponding author. E-mail: qiuyunliang@163.com

Received September 15, 2020; revised November 18, 2020; published online December 4, 2020.

Project supported by the Special Funds for Fundamental Scientific Research of Central Universities (No. LGZD202006) and the College Students' Practice and Innovation Training Program (Nos. 201912213019G, 201912213023G).

中央高校基本科研业务费专项(No. LGZD202006)和大学生实践创新训练计划(Nos. 201912213019G, 201912213023G)资助项目.
} 


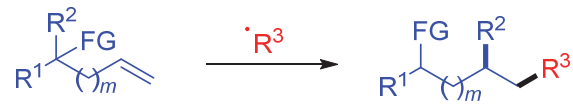

图 1 自由基促进的分子内迁移

Figure 1 Radical prompted intramolecular migration

因此含三氟甲基的化合物被广泛地应用于医药、农药和 材料等领域中(图 2) ${ }^{[3]}$. 例如, 抗精神病类药物哈拉西泮 (Halazepam $)^{[4]}$ 、消化系统用药兰索拉唑(Lansoprazole $)^{[5]}$ 、 治疗内分泌和代谢药物氟骨三醇(Falecalcitriol) ${ }^{[6]}$ 、治疗 心脑血管类药物多噻嗪(Polythiazide $)^{[7]}$ 和坎格雷洛四钠 盐(Cangrelor Tetrasodium) ${ }^{[8]}$ 等, 都含有三氟甲基的结构 单元，是具有良好生物活性的三氟甲基类药物分子.<smiles>O=C1CN=C(c2ccccc2)c2cc(Cl)ccc2N1CC(F)(F)F</smiles>

Halazepam
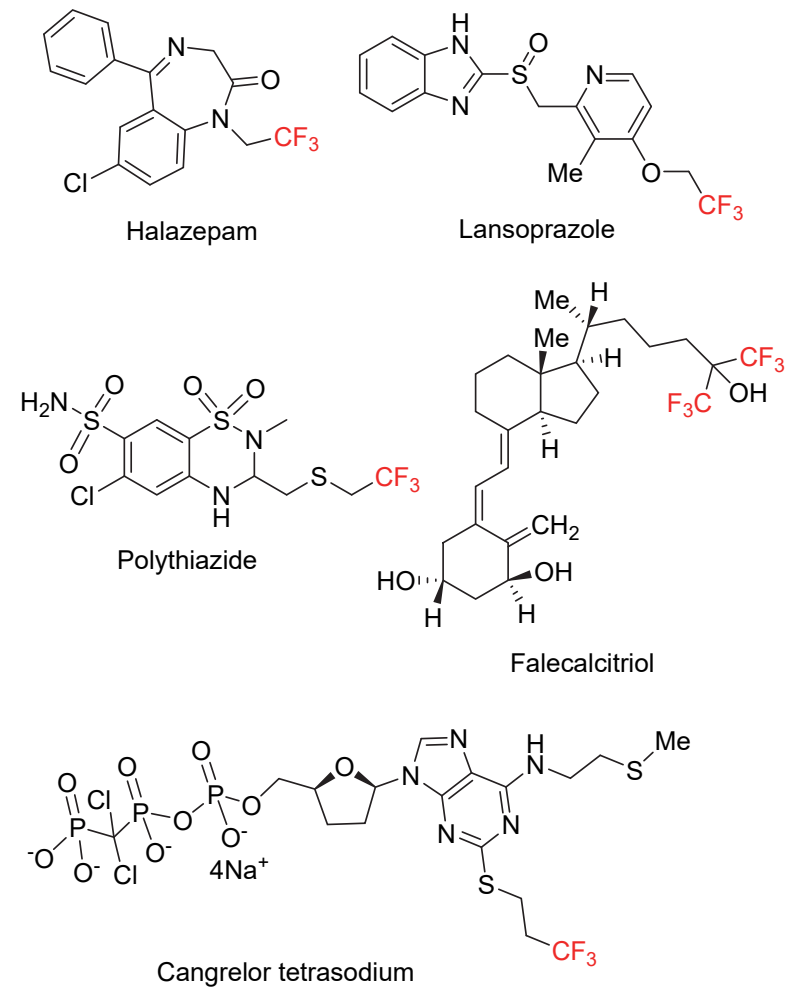

图 2 含有三氟甲基的药物分子

Figure 2 Drug molecules containing trifluoromethyl groups

关于引入三氟甲基的文献有很多，包括亲核取代、 亲电取代以及自由基反应等 ${ }^{[9]}$. 近年来, 通过烯烃的三 氟甲基化引发的分子内官能团迁移反应得到了广泛的 关注, 该策略为实现烯烃的双官能团化提供了直接高效 的方法, 为含有三氟甲基官能团化新分子的合成提供了 新的合成手段. 该方法以广泛存在的烯烃为反应原料, 使用三氟甲基试剂产生的三氟甲基自由基，引发分子内 官能团的迁移, 可以在温和的条件下实现烯烃的双官能 团化. 常用的产生三氟甲基自由基的试剂有 Togni 试 剂、Umemoto 试剂、Langlois 试剂及三氟碘甲烷等(图 3). 关于自由基迁移的综述, 已经有过一些报道 ${ }^{[10]}$.
2019 年, 张前课题组发表了自由基促进的不饱和键的 迁移反应，分别从不饱和双键和不饱和参键的角度说明 了迁移反应的特点 ${ }^{[10 \mathrm{e}]}$. 最近, 朱晨课题组总结了自由 基促进的远程官能团迁移反应，分类讨论了自由基促进 的非活化烯烃双官能团化 ${ }^{[10 f]}$. 本文通过对三氟甲基自 由基促进的烯烃的双官能团化反应的总结性研究，根据 参与反应的烯烃的种类不同，分为官能团化烯烃和非活 化烯烃两大部分, 分别讨论了不同方式的自由基产生途 径、不同类型官能团的迁移形式以及研究现状.<smiles>CC1(C)OI(C(F)(F)F)c2ccccc21</smiles>

Togni's reagent I

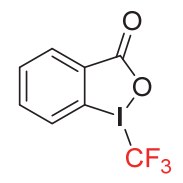

Togni's reagent II

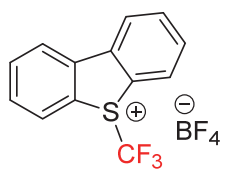

Umemoto's reagent

$$
\begin{array}{cc}
\mathrm{CF}_{3} \mathrm{SO}_{2} \mathrm{Na} & \mathrm{CF}_{3} \mathrm{I} \\
\text { Langlois' reagent } & \text { trifluoroiodomethane }
\end{array}
$$

图 3 常见的产生三氟甲基自由基的试剂

Figure 3 Common reagents generating trifluoromethyl radicals

\section{1 活化烯烃的三氟甲基化}

\subsection{1,2-芳基迁移}

三氟甲基自由基进攻双键，进一步引发二芳基烯丙 醇类化学物的重排，该重排反应主要是通过 1,2-芳基迁 移进行的，形成 $\beta$-三氟甲基- $\alpha$-芳基酮类化合物. 2013 年， 吴䈗星和李鹏飞课题组 ${ }^{[11]}$ 发展了二芳基烯丙醇类化合 物 1 与 Togni's reagent II 的三氟甲基化反应(Scheme 1). 该反应采用 $10 \mathrm{~mol} \%$ 的碘化亚酮为催化剂, $N, N$-二甲基 甲酰胺为溶剂，在 $50{ }^{\circ} \mathrm{C}$ 的反应温度下，以中等到良好 的产率合成了一系列 $\beta$-三氟甲基- $\alpha$-芳基酮类化合物 2 . 作者结合理论计算预测了该反应的自由基历程: 首先三 氟甲基试剂 Togni's reagent II 与一价铜发生单电子转移 生成三氟甲基自由基和二价铜物种; 随后三氟甲基自由 基进攻化合物 1 的双键，形成碳自由基中间体 3; 中间 体 3 的自由基中心进攻缺电子的芳烃形成三元环过渡态 中间体 4, 再发生 1,2-芳基迁移得到中间体 5; 最后中间 体 5 进一步被二价铜单电子氧化, 并脱掉一个质子形成 最终的产物 2 .

随后，涂永强课题组 ${ }^{[12]}$ 报道了半频哪醇类化合物 6 的三氟甲基化/1,2-芳基迁移反应(Scheme 2,a). 反应在 溴化亚铜和醋酸亚铜的共同催化下进行, 选用 Togni's reagent II 作用三氟甲基自由基源，该反应具有较好的官 能团兼容性. 当 $\mathrm{R}^{1}$ 和 $\mathrm{R}^{2}$ 分别为芳基和烷基时，芳基高 选择性地优先发生 1,2-迁移，得到相应的产物. 当 $\mathrm{R}^{1}$ 和 $\mathrm{R}^{2}$ 为四元环或五元环时，则发生烷基迁移，得到相应的 扩环类产物. 
Li and Wu, 2013

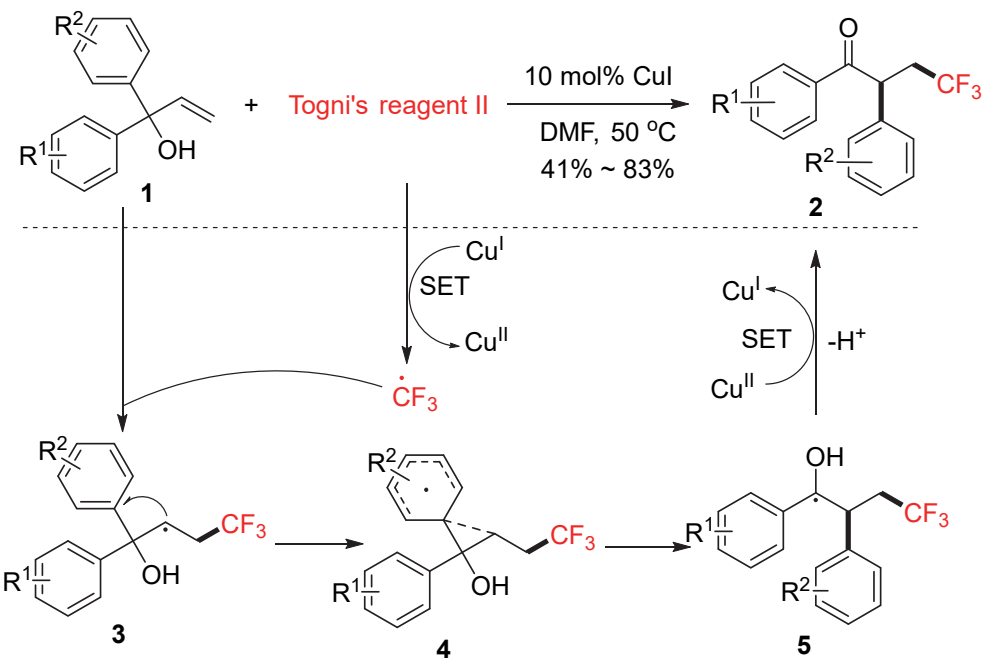

图式 $1 \mathrm{Cu}$ 催化的二芳基烯丙醇的 1,2-迁移反应

Scheme 1 Cu-catalyzed 1,2-migration of diaryl-substituted allylic alcohol

(a) Tu, 2013

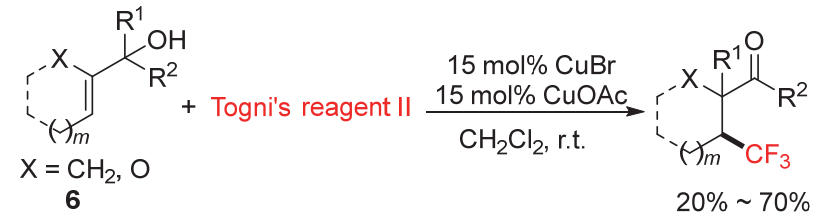

(b) Sodeoka, 2013

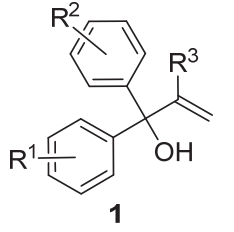

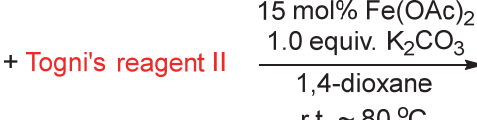

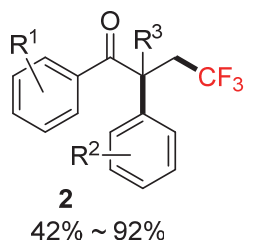

(c) Zhu, 2015

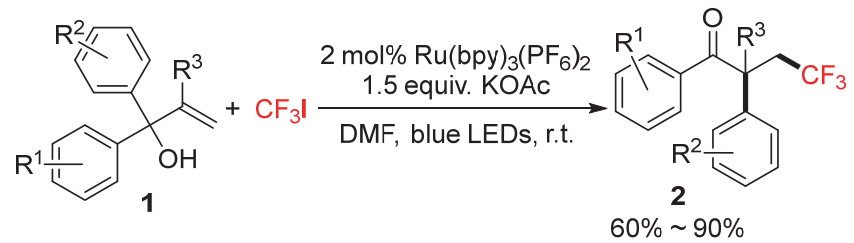

(d) Yang and Xia, 2015
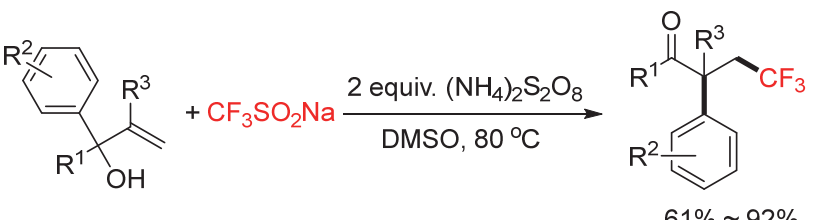

(e) Cai, 2018

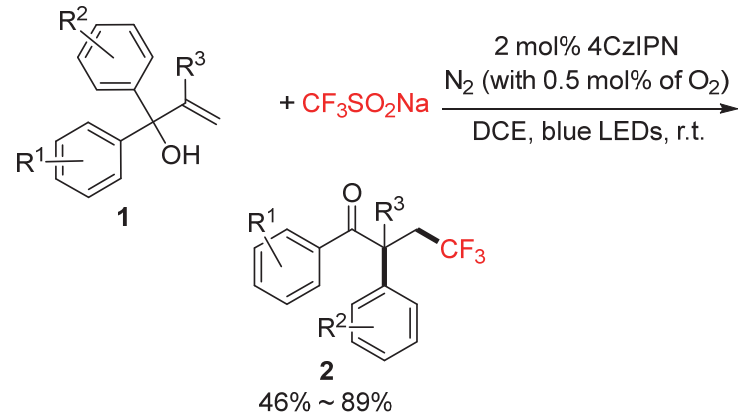

(f) $\mathrm{Yu}, 2018$

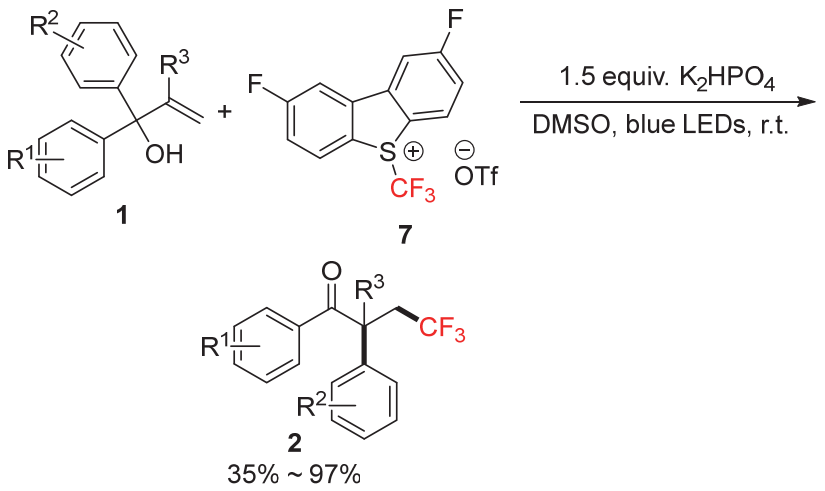

(g) Lei, 2019

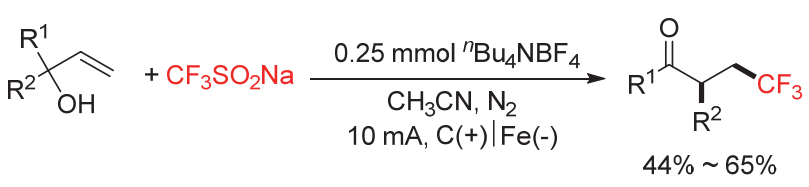

图式 2 不同催化体系下二芳基烯丙醇的 1,2-迁移反应

Scheme 2 1,2-Migration of diaryl-substituted allylic alcohols under different catalytic systems 
此后, 许多课题组在这一领域进行了研究, 发展了 多种高效的催化体系. Sodeoka 课题组 ${ }^{[13]}$ 使用 $15 \mathrm{~mol} \%$ 的醋酸亚铁为催化剂也可以高效催化化合物 1 与 Togni's reagent II 试剂发生单电子转移, 生成中间体 $\mathbf{3}$, 并进一步发生 1,2-芳基迁移, 生成 $\beta$-三氟甲基- $\alpha$-芳基酮 类化合物 2 (Scheme 2, b). 2015 年, 朱成建课题组 ${ }^{[14]}$ 首 次使用三氟碘甲烷为三氟甲基源, 在蓝光的照射和光催 化剂 $\mathrm{Ru}(\mathrm{bpy})_{3}\left(\mathrm{PF}_{6}\right)_{2}$ 的作用下, 实现了烯烃的双官能团 化(Scheme 2, c). 此外, Langlois 试剂 $\left(\mathrm{CF}_{3} \mathrm{SO}_{2} \mathrm{Na}\right)$ 也可以 在过二硫酸铵 (Scheme 2, d $)^{[15]}$ 或光催化剂 $4 \mathrm{CzIPN}$ (Scheme 2, e $)^{[16]}$ 的作用下产生三氟甲基自由基, 促进 1,2-芳基迁移产物的生成. 俞寿云课题组 ${ }^{[17]}$ 发展了二芳 基烯丙醇类化合物 1 与试剂 7 的芳基三氟甲基化反应 (Scheme 2, f). 该反应不需要额外的光催化剂的参与, 仅在蓝光的照射下, 试剂 7 就可以生成三氟甲基自由基. 作者着重考察了反应的迁移选择性: 缺电子的芳烃或杂 芳烃在标准条件下优先发生迁移. 雷爱文课题组 ${ }^{[18]}$ 使 用电化学方法产生三氟甲基自由基, 也可以实现烯丙醇 类化合物的 1,2-迁移反应(Scheme 2, g). 该方法使用碳
和铁电极，在 $10 \mathrm{~mA}$ 的持续电流下进行，不仅适用于芳 基迁移，也适用于烷基迁移，以中等产率得到迁移后的 烯烃双官能团化产物. 对于环状化合物开环重排同样适 用，成功实现了四到十五元环的开环重排. 随着环的增 大，迁移效率明显降低，三氟甲基化的十六元环产物只 有 $28 \%$ 的收率.

\subsection{1,2-烷基迁移}

通过自由基诱导的烯烃官能团化，可以引发张力环 的开环重排，构建扩环的环酮类化合物 ${ }^{[19] .} 2015$ 年, Glorius 课题组 ${ }^{[20]}$ 发展了光催化的半频那醇重排三氟甲 基化反应(Scheme 3). 该过程在光催化剂钌的作用下进 行，光照作用下二价钌催化剂生成激发态的钌，与 Umemoto 试剂发生单电子转移生成三价钉和三氟甲基 自由基. 环丁醇类化合物 8 原位生成硅醚类化合物 $\mathbf{1 0}$, 随后接受三氟甲基自由基的进攻形成中间体 11. 中间 体 11 与三价钓通过进一步的单电子转移完成金属钉的 催化循环，同时生成中间体 12. 环丁基碳正离子经过 1,2-碳重排生成中间体 $\mathbf{1 3}$, 最后经脱保护得到理想的产

Glorius, 2015
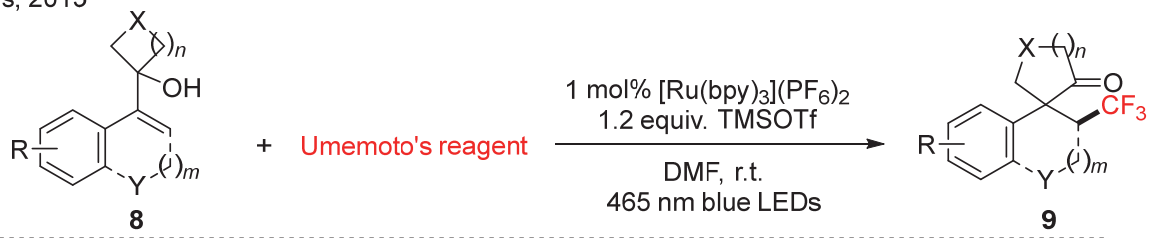

Kim, 2015
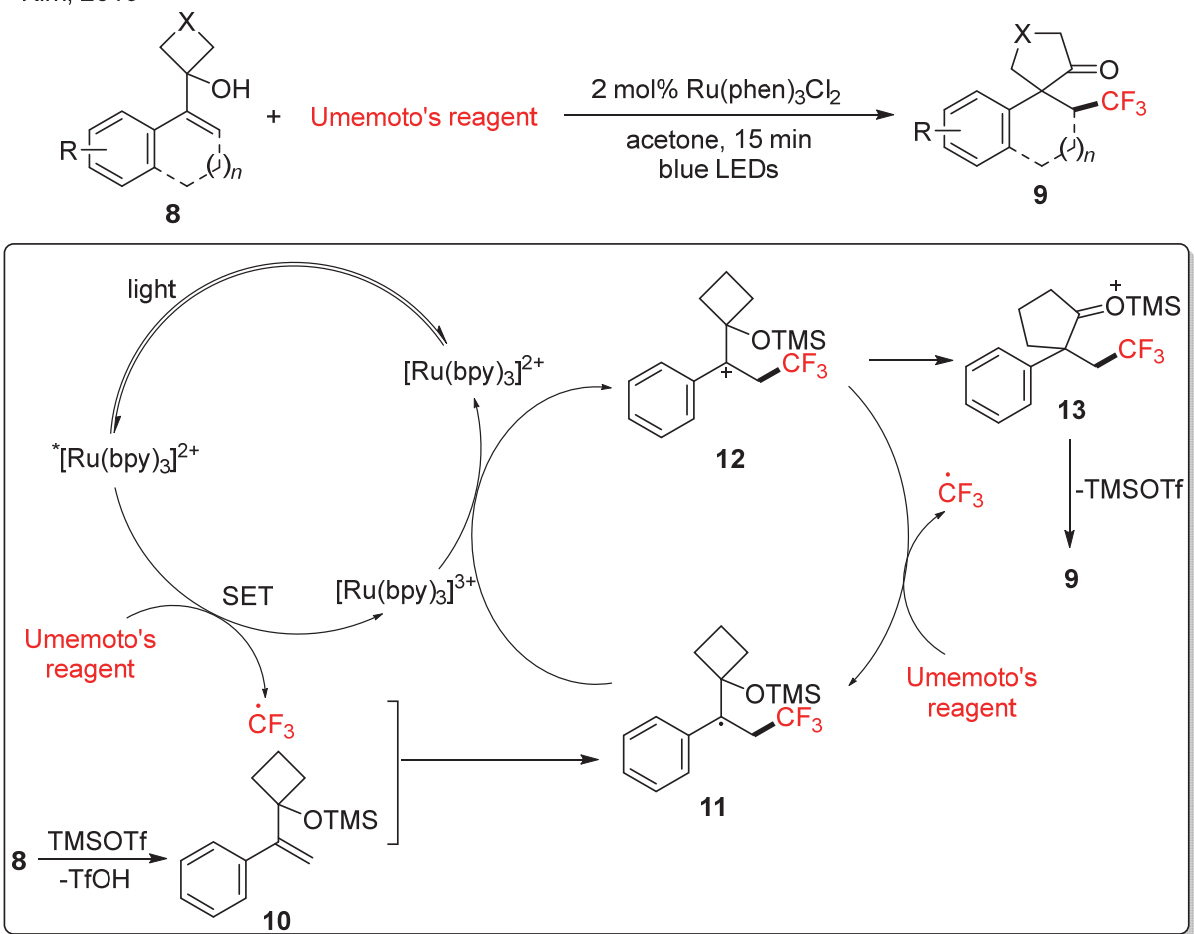

图式 3 光催化的三氟甲基化/半频那醇重排反应

Scheme 3 Photocatalytic trifluoromethylation/semi-pinacol rearrangement 
物 9. 该方法不仅适用于四元环, 对于四元杂环和五元 环同样适用，可以得到相应的扩环三氟甲基化产物. 同 年, Kim 课题组 ${ }^{[21]}$ 报道了类似的过程. 与 Glorius 的方法 不同, 采用 Kim 的方法, 光催化的三氟甲基化/半频哪醇 重排反应可以在 $15 \mathrm{~min}$ 内高效率地完成, 并且醇羟基不 需要通过硅醚的保护即可进行反应.

2019 年, 陈志敏和张书宇课题组 ${ }^{[22]}$ 采用电化学的 方式实现了烯基环丁醇类化合物 10 的三氟甲基化扩环 重排反应(Scheme 4). 该策略以三氟甲磺酸钠为三氟甲 基源, 碳电极作阳极, 铂电极作阴极, 在 $15 \mathrm{~mA}$ 的持续 电流下进行. 三氟甲磺酸阴离子在阳极区域失去一个电 子生成三氟甲磺酸自由基, 随后失去一分子二氧化硫形 成的三氟甲基自由基与化合物 10 的双键反应，并进一
步发生开环重排生成 11. 而在阴极区域，水分子得到一 个电子生成羟基阴离子和氢气. 乙腈与水作为混合溶剂 可以有效地抑制分子内环氧副产物的生成, 当芳环上含 有吸电子基团时，不能得到理想的开环三氟甲基化产物 11. 同时, Kim 课题组 ${ }^{[23]}$ 也报道了在水和乙腈的混合体 系中采用电化学策略产生三氟甲基自由基, 促进烯基环 丁醇扩环的方法. 与之前方法不同的是, Kim 使用 Pt 电 极作为阳极, 在 $3 \mathrm{~mA}$ 的持续电流下即可以得到很好的 反应结果.

\subsection{1,2-炔基迁移}

2019, 梁永民课题组 ${ }^{[24]}$ 在研究化合物 12 与三氟甲 磺酸钠的反应时，使用叔丁基过氧化氢作用引发剂，以 中等产率得到了炔基 1,2-迁移的产物 $\mathbf{1 3}$ (Scheme 5).

Chen and Zhang, 2019<smiles></smiles>

10
3.0 equiv. $\mathrm{LiClO}_{4}$ $\mathrm{C} / \mathrm{Pt}$ undivided cell $\mathrm{MeCN} / \mathrm{H}_{2} \mathrm{O}(V: V=2: 1)$ $15 \mathrm{~mA}$

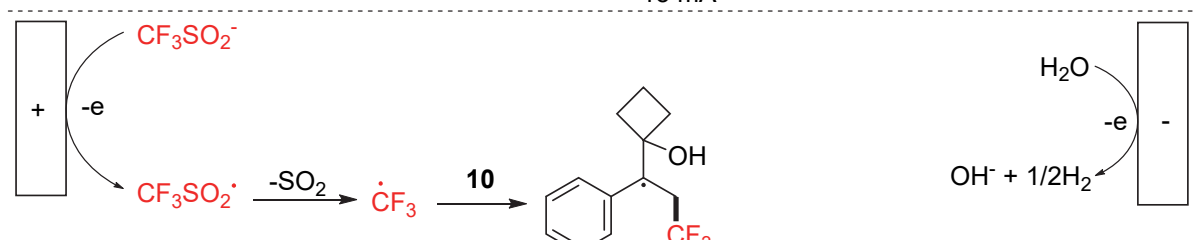

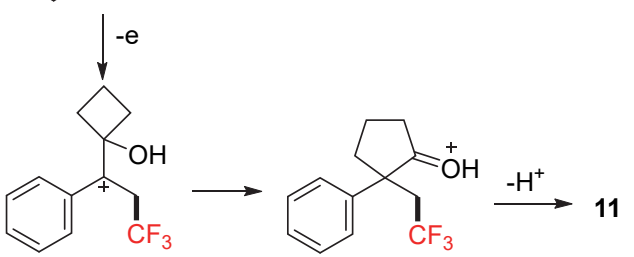<smiles></smiles>

10

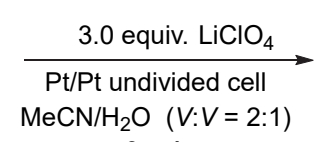

$3 \mathrm{~mA}$<smiles>O=C1NCCC1(CC(F)(F)F)c1ccccc1</smiles>

11

图式 4 电化学促进的烯基环丁醇的开环反应

Scheme 4 Electrochemical promoted ring-opening reaction of alkenyl cyclobutanol

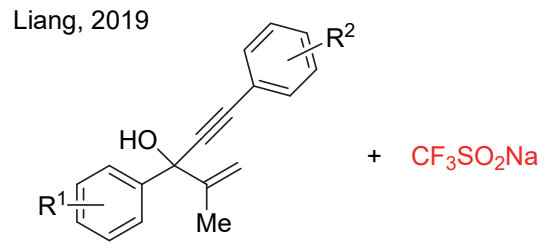

12

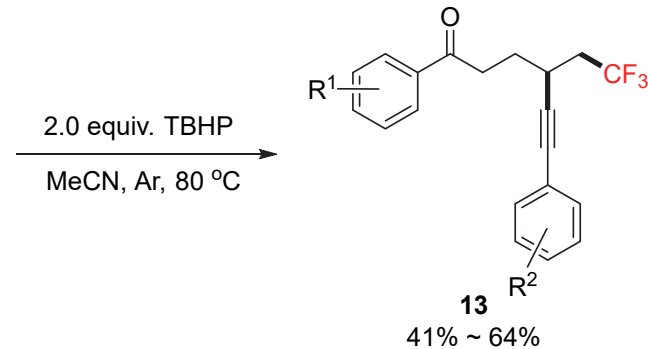

图式 5 1,2-炔基迁移反应

Scheme 5 1,2-Alkynyl migration reaction 


\subsection{1,5-芳基迁移}

2013 年, Nevado 课题组 ${ }^{[25]}$ 设计合成了 $N$-磺酰基保 护的烯基酰胺类化合物 14 , 在铜的催化作用下与三氟 甲基试剂 Togni's reagent II 反应，一锅法实现了三氟甲 基化/芳基迁移/脱磺酰基化反应，构建了含有季碳中心 的酰胺类化合物 15 或三氟甲基化氧化吲哚类化合物 16 (Scheme 6). 并通过控制实验明确了反应经由自由基的 机理: 首先, Togni's reagent II 试剂与一价铜发生单电子 转移生成三氟甲基自由基和二价铜物种, 三氟甲基自由 基进攻烯烃形成自由基 17; 随后自由基中心进攻与磺 酰胺相连的芳环发生 1,5-芳基迁移，形成中间体 18; 中 间体 18 经过开环及脱磺基等过程生成氨基自由基 19 . 当氮原子上的取代基为给电子的烷基时, 19 与二价铜发 生单电子转移形成中间体 20, 并进一步被芳环捕获, 得 到氧化吲哚类化合物 16; 当氮原子上的取代基为芳基 时, 19 与二价铜发生单电子转移后则筫取介质中的质子 生成化合物 $\mathbf{1 5}$.
进一步地，通过在磺酰基相连的芳基邻位上引入不 同的官能团可以设计合成多种官能团化的杂环类化合 物. 当引入炔基官能团时, 所形成的氮自由基 19 先进攻 炔基，生成乙烯基自由基，随后进攻芳环生成官能团化 的多环类化合物 21 (Scheme 7) ${ }^{[26]}$. 除了三氟甲基自由基 外，硫三氟甲基自由基、重氮自由基、二苯基亚膦酸自 由基以及 1,3-二羰基酮都可以促进这类多步反应的发 生 ${ }^{[27]}$.

\section{2 非活化烯烃的三氟甲基化}

自由基诱导的分子内迁移策略为非活化烯烃的多 元化转化提供了可能，该方法可以在温和的条件下实现 $\mathrm{C}-\mathrm{C}$ 键的断裂和重组，具有良好的官能团兼容性和选 择性, 为复杂分子的构建提供了高效直接的策略. 近年 来，关于非活化烯烃的研究取得了重大的进展，下面根 据迁移基团的不同进行分类介绍.

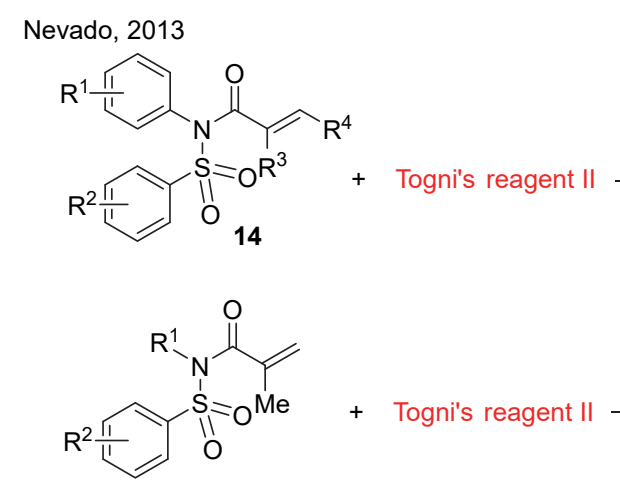

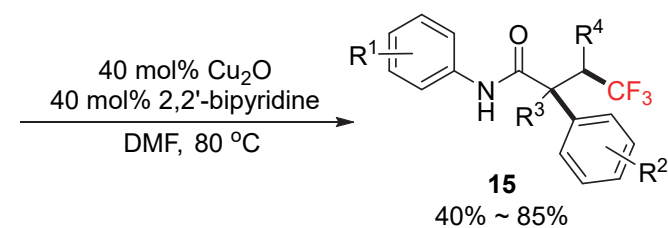

$20 \mathrm{~mol} \% \mathrm{Cu}\left(\mathrm{CH}_{3} \mathrm{CN}\right)_{4} \mathrm{PF}_{6}$ 2.0 equiv. $2,2^{\prime}$-bipyridine $\mathrm{MeCN}, 80^{\circ} \mathrm{C}$

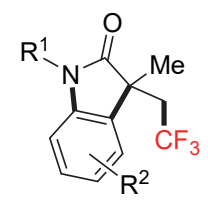

16

$48 \% \sim 72 \%$
14

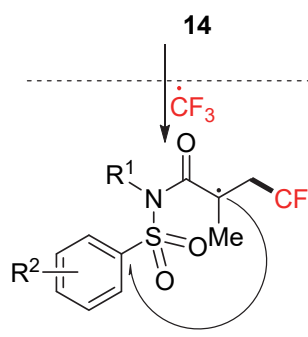

17

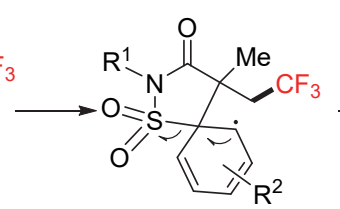

18

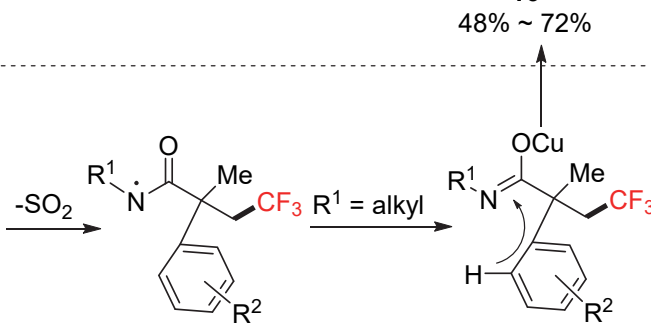

19

20

图式 6 铜催化的三氟甲基化/芳基迁移/脱磺酰化反应

Scheme $6 \mathrm{Cu}$-Catalyzed trifluoromethylation/aryl migration/desulfonylation reaction Nevado, 2015

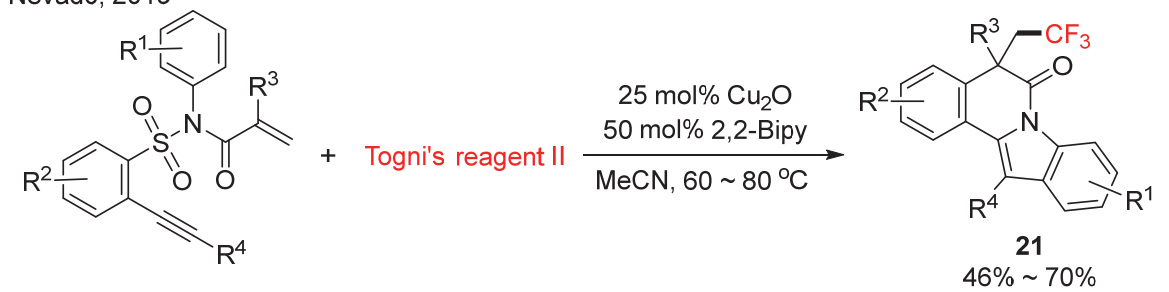

图式 7 三氟甲基官能团化的多环类化合物的设计合成

Scheme 7 Design and synthesis of trifluoromethyl functionalized polycyclic compounds 


\section{1 氢迁移}

2014 年, 刘心元课题组 ${ }^{[28]}$ 报道了 $\mathrm{Cu}$ 与 Brønsted 酸 23 共同催化的非活化烯烃的氢三氟甲基化反应(Scheme 8). 该方法涉及 1,5-氢迁移的关键步骤, 同时形成的亚 胺中间体 25 在 Brønsted 酸 23 的催化作用下高对映选择 性地引入 $\mathrm{C}-\mathrm{O}$ 键, 实现手性化合物 $\mathbf{2 4}$ 的合成. 通过机 理研究发现, 在反应体系中不仅通过 Brønsted 酸控制了 手性中心的形成, 同时通过活化试剂 Togni's reagent I增 加了反应的速率. 该反应对于各种官能团都具有良好的 兼容性, 各种烷基醇和芐醇都可以高 $e e$ 值地得到相应 的手性化合物, 为三氟甲基自由基引发的远程 $\mathrm{C}-\mathrm{H}$ 键 官能团化提供了高效地策略.

此外, 使用催化量的 1,2-双 (二苯基膦基)苯也可以 促进 1,5-氢迁移的发生(Scheme 9 ${ }^{[29]}$. 三氟甲基自由基 首先被烯烃捕获, 再发生 1,5 -氢迁移、单电子转移和去 质子化, 得到关键的中间体 30.30 进一步接受三氟甲基 自由基的进攻, 高产率、高化学选择性和立体选择性地
得到双三氟甲基取代的烯胺类化合物 27. 进一步可以 设计一锅法的环化反应得到双三氟甲基取代的噁唑啉 类化合物 29. 机理实验表明, 该反应是通过膦催化的非 活化烯烃的自由基三氟甲基化过程进行的.

2015 年, 谭斌和刘心元课题组 ${ }^{[30]}$ 继续研究铜催化 的非活化烯烃的自由基氢三氟甲基化，首次利用酮的 $\alpha$ 位氢 1,5-氢迁移实现了该过程, 并在酮的 $\alpha$ 位成功引入 了叠氮基团, 为进一步合成含有三氟甲基的内酰胺骨架 提供了可能(Scheme 10). 此外, 其它的亲核试剂, 如 溴、氯、碘和氧基等都可以被成功地引入酮的 $\alpha$ 位, 实 现三氟甲基自由基促进的 1,6 双官能团化反应 ${ }^{[31-32]}$.

2016 年, 朱钢国课题组 ${ }^{[33}$ 通过三氟甲基自由基诱 导的醛氢 1,5-迁移策略在室温条件下实现了非活性烯烃 的氢三氟甲基化(Scheme 11). 明显地, 在反应体系中加 入氨作为亲核试剂可以得到三氟甲基取代的酰胺类化 合物.

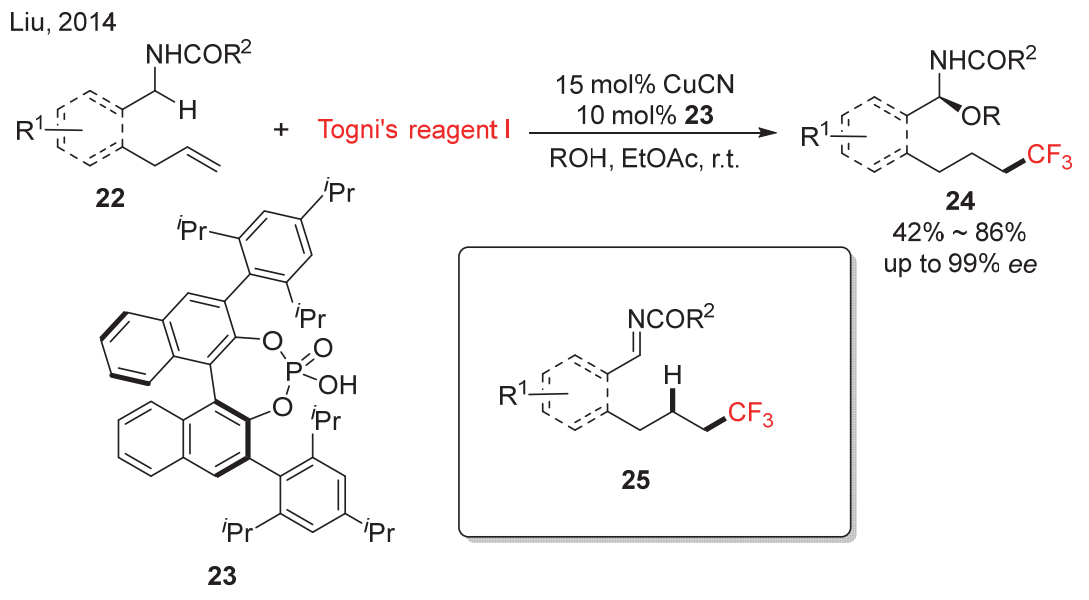

图式 $8 \mathrm{Cu}$ 与 Brønsted 酸共同催化的非活化烯烃的氢三氟甲基化反应

Scheme 8 Hydrotrifluoromethylation of non-activated alkenes under the co-catalyst of $\mathrm{Cu}$ and Brønsted acid

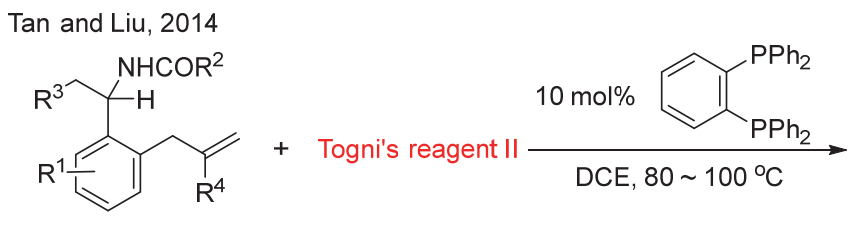

26<smiles>C=CCc1ccc[R1]c1C(C)NC=O</smiles>

28 DCE, $80 \sim 100^{\circ} \mathrm{C}$
then PIFA, r.t.

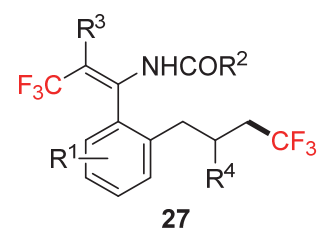

$65 \% \sim 98 \%$

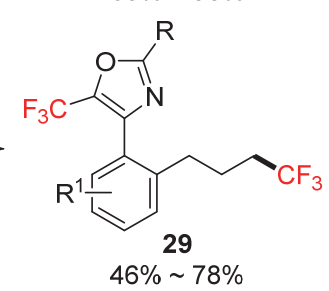

$46 \% \sim 78 \%$

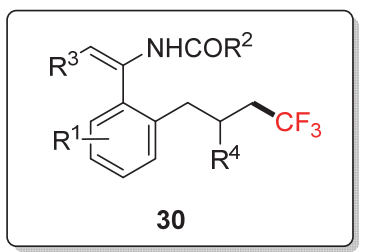

图式 9 有机膦催化的 1,5 -氢迁移过程

Scheme 9 Organophosphine-catalyzed 1,5-hydrogen migration 
Liu, 2015

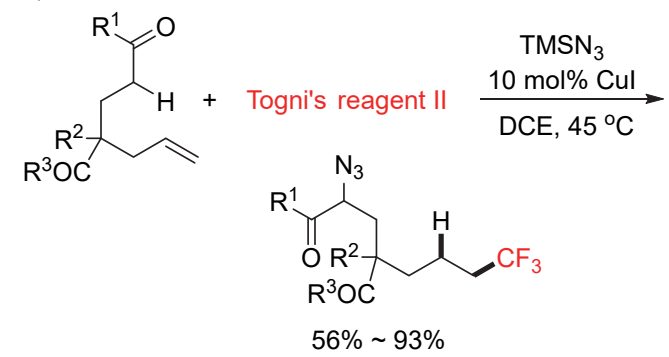

图式 10 铜催化的 1,5-氢迁移过程

Scheme 10 Cu-Catalyzed 1,5-hydrogen migration

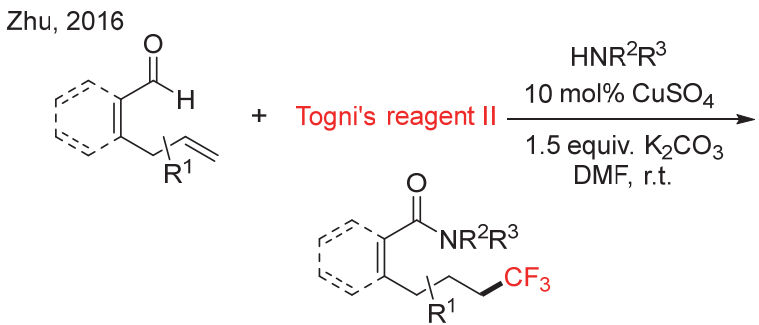

up to $87 \%$ yield

图式 11 三氟甲基自由基促进的醛氢的 1,5-氢迁移 Scheme 11 Trifluoromethyl radical promoted 1,5-hydrogen migration of aldehyde group

随后, Chiba 和 Gagosz 课题组 ${ }^{[34]}$ 以苄基保护的丁烯 醇或丁烯胺为原料, 与 Togni's reagent II 试剂在铜的催 化下反应，实现烯烃氢三氟甲基化的同时，完成了羟基 与氨基的脱苠基过程(Scheme 12). 该反应在 $60{ }^{\circ} \mathrm{C}$ 条件 下进行, 底物兼容范围广泛, 各种茮基保护的醇和氨类 均可实现其远端烯烃的氢三氟甲基化. 机理研究实验认 为: 反应过程通过三氟甲基自由基引发，进攻化合物 31
的双键，形成自由基 32; 该自由基发生 1,5-氢迁移形成 新的自由基物种 $33 ; 33$ 进一步与二价铜发生单电子转移 得到中间体 34, 并在体系中亲核试剂甲醇的进攻下得 到化合物 35.35 的活性比较高，容易在酸作用下脱保护， 生成带有活泼氢的羟基或氨基类化合物.

\section{2 芳基迁移}

自由基促进的芳基迁移是一类非常重要的有机转 化, 可以高效地实现非活化烯烃的双官能团化 ${ }^{[35]} .2016$ 年, 刘心元课题组 ${ }^{[36]}$ 报道了铜催化的烯醇类化合物 36 与试剂 Togni's reagent II 反应生成三氟甲基取代的中环 类化合物 37 的反应(Scheme 13). 该反应对于构建含三 氟甲基的八到十一元环具有十分重要的意义. 对于双取 代的端烯类化合物 38, 催化量的三氮杂双环癸烯可以 促进反应的进行, 以 $41 \%$ 的产率, $2 / 1$ 的 $d r$ 值得到九元环 化合物 39. 当使用手性醇 40 作为底物时, 可以以 $64 \%$ 的产率对映选择性完全保留地得到手性中环类化合物 41. 此外, 通过密度泛函理论(DFT)计算, 提出了如下的 反应机理：首先，三氟甲基自由基与化合物 $\mathbf{3 6}$ 中的双键 反应，形成的碳自由基分别从两个方向进攻芳环. 通过 过渡态 42 和 43 分别需要克服 62.0 和 $67.8 \mathrm{~kJ} / \mathrm{mol}$ 的能 量, 这是产物对映体保持的根本原因. 中间体 44 跨越 $40.2 \mathrm{~kJ} / \mathrm{mol}$ 的能垒实现 $\mathrm{C}-\mathrm{C}$ 键的断裂, 完成中环骨架 的构建. 除了构建中环以外, 非环状的底物也可以成功 地进行 1,4-芳基迁移和 1,5-芳基迁移，得到链式的烯烃 双官能团化产物 ${ }^{[37]}$. 对于含有不同取代基的芳基或杂 芳基, 迁移是有选择性的, 缺电子的芳环或杂芳环优先 发生迁移反应.

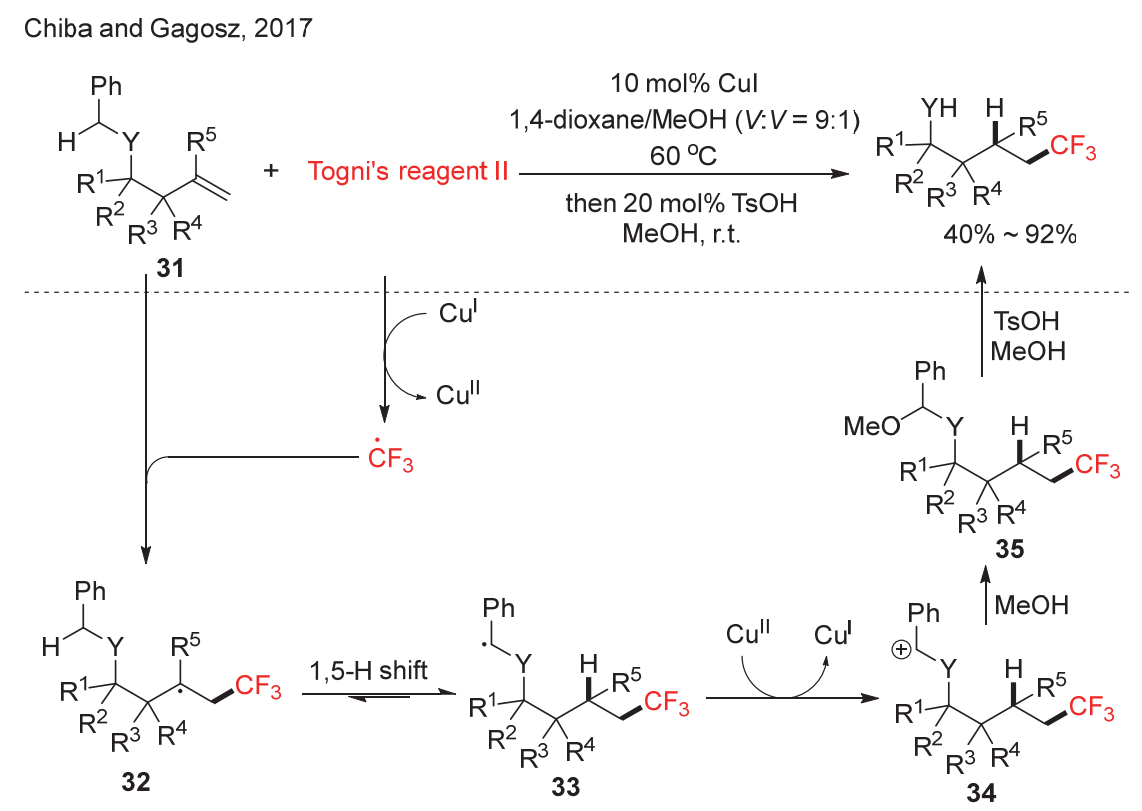

图式 12 三氟甲基自由基促进的苄氢的 1,5-氢迁移

Scheme 12 Trifluoromethyl radical prompted 1,5-hydrogen migration of benzyl hydrogen 
Liu, 2016

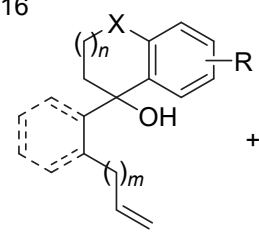

36

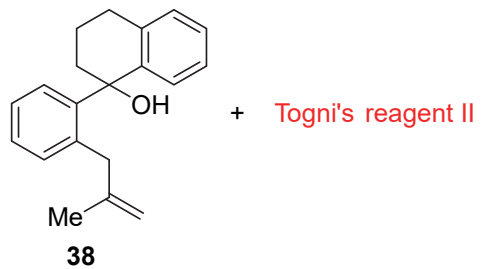

38

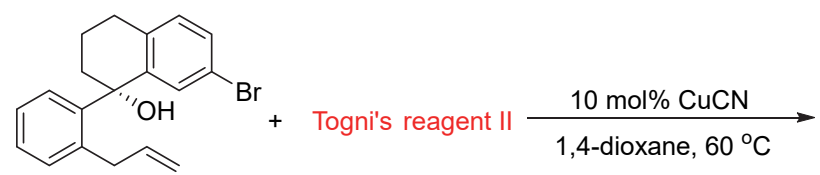

40

$99 \%$ ee
Togni's reagent II $\underset{\text { solvent, } 60 \sim 100^{\circ} \mathrm{C}}{\stackrel{10 \mathrm{~mol} \% \mathrm{CuCN}}{\longrightarrow}}$

$m=0,1$

$n=0,1,2$

$\mathrm{X}=\mathrm{CH}_{2}, \mathrm{O}, \mathrm{NTs}, \mathrm{S}$

EtOAc, $100^{\circ} \mathrm{C}$

4-dioxane, $60^{\circ} \mathrm{C}$

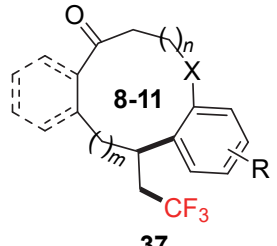

37

$30 \% \sim 75 \%$<smiles>CC(CC(F)(F)F)C1CCCCCC(=O)c2ccccc21</smiles>

39

$41 \%, 2: 1 d r$

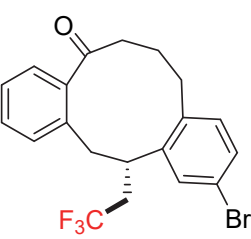

41

$64 \%, 96 \%$ ee

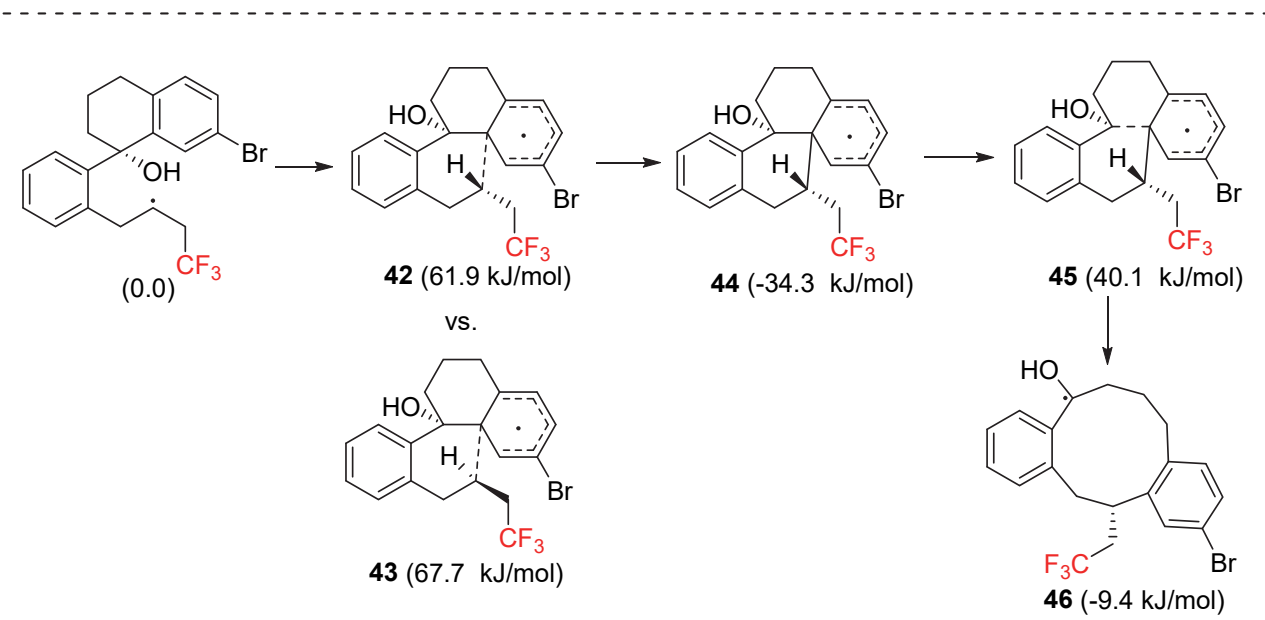

图式 13 通过芳基迁移策略构建中环骨架

Scheme 13 Construction of medium ring skeleton via the strategy of aryl migration

2017 年, 朱晨课题组 ${ }^{[38]}$ 系统地研究了杂芳环的远 程迁移能力, 在温和的条件下合成了一系列含氟杂芳环 类化合物 (Scheme 14). 这是首例通过远程杂芳环迁移 的非活化烯烃的双官能团化. 该反应使用高价碘化物作 为引发剂, 三氟甲磺酸钠为三氟甲基自由基前体, 随后 发生杂芳基迁移, 实现 $\mathrm{C}-\mathrm{C}$ 键的断裂和重组. 在底物 扩展中发现, 缺电子的芳环更容易发生迁移. 为了进一 步明确迁移反应的机制, 作者合成了不同链长的烯醇类 化合物 47.47 在标准条件下与三氟甲磺酸钠反应, 当 $n=0$ 时, 通过三元环过渡态完成 1,2-芳基迁移; 进一步 增长碳链的长度发现, 除了 1,2-芳基迁移、1,4-芳基迁移 和 1,5-芳基迁移都是可行的，而 1,3-芳基迁移和 1,6-芳 基迁移不能实现.
最近, Hong 课题组 ${ }^{[39]}$ 报道了光引发的吡啶环的邻 位选择性迁移反应，实现了非活性烯烃的三氟甲基化吡 啶化反应(Scheme 15). 在光照和光催化剂的条件下, 三 氟甲磺酸钠产生的三氟甲基自由基进攻双键得到烷基 自由基中间体. 该烷基自由基中间体亲核进攻吡啶盐的 邻位, 并经过进一步的单电子转移、 $\mathrm{N}-\mathrm{O}$ 键断裂、质 子化从而得到相应的产物. 二取代和三取代的烯烃都能 很好地兼容, 当在吡啶的 3 号或 5 号位引入不同的取代 基时，反应表现出一定的选择性. 为了证明该方法的实 用性，作者成功将其应用于复杂生物分子的后期官能团 化修饰中, 并以中等收率得到了相应的烯烃双官能团化 产物. 对于不同链长的化合物进行比较发现，对于丙烯 醇类氮氧化合物, 其通过五元环过渡态形成的双 

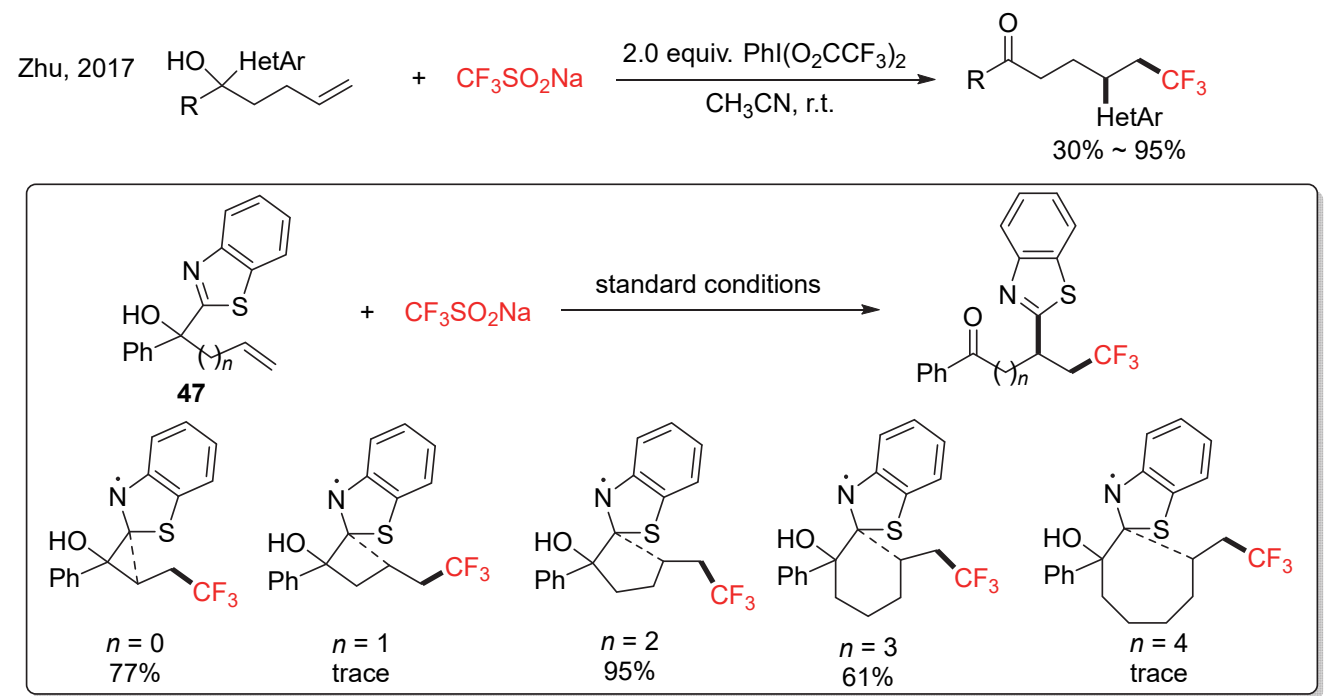

图式 14 远端杂芳基迁移的区域选择性考察

Scheme 14 Investigation on the regioselectivity of remote heteroaryl migration

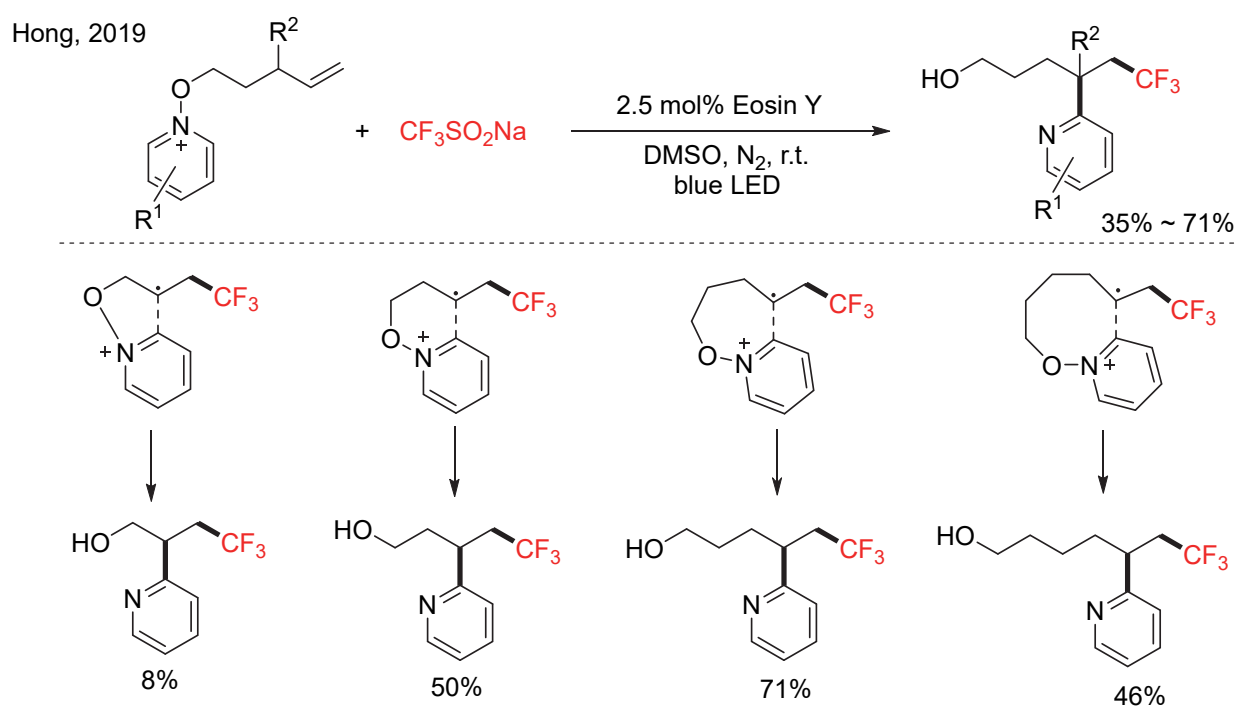

图式 15 光催化下吡啶环上的邻位选择性迁移

Scheme 15 Photocatalyzed ortho-selective migration on pyridyl ring

官能团化产率效率很低; 相应的六元环过渡态、七元环 过渡态和八元环过渡态都可以以中等到良好的产率得 到相应的烯烃双官能团产物.

\section{3 烯基迁移}

2017 年, 刘心元课题组 ${ }^{[40]}$ 开发了首例铜催化的三 氟甲基自由基促进的烯基迁移反应，实现了非活化烯烃 的三氟甲基化/烯基化双官能团化反应，合成了一系列 含氟类化合物 49 (Scheme 16). 该方法对于 1,3-烯基迁 移、1,4-烯基迁移及 1,5 -烯基迁移都适用. 当使用环状的 烯丙醇类化合物 50 为原料时, 在标准条件下与 Togni's reagent II 试剂反应可以以优秀的化学选择性和立体选 择性得到含有三氟甲基的八到十四元环类化合物 51 .

随后, Studer 课题组 ${ }^{[41]}$ 发展了无金属参与的烯丙醇
类化合物 52 与多氟碘代物的反应. 该方法使用 1,4-二氮 杂二环[2.2.2]辛烷(DABCO)作为引发剂, 引发全氟烷烃 自由基的生成. 三氟碘甲烷作为气体也可参与反应，在 标准条件下, 发生 1,4-烯基迁移，以 76\%的产率得到相 应的三氟甲基/烯基双官能团化产物 53 (Scheme 17).

\section{4 炔基迁移}

炔基也可以发生迁移, 2017 年, 朱晨课题组 ${ }^{[42]}$ 首次 在光催化条件下通过三氟甲基自由基诱导实现了分子 内的炔基迁移反应(Scheme 18). 该反应的特点是使用 Umemoto 试剂为三氟甲基源, 在蓝光的照射下, 室温下 即可以高效地完成. 温和的反应使得底物具有较好的官 能团兼容性. 该反应的催化循环如下: 首先在光照条件 下，铱催化剂被激发生成激发态的铱，与 Umemoto 试剂 
Liu, 2017<smiles>[R]C=CC([R])(O)c1c[R1]#ccc1NC([R7])C</smiles>

48

$m=-1,0,1$<smiles>[R]C=CC([R])(Cc1cc[R17]([H])cc1C([R])=O)CC(F)F</smiles>

$30 \% \sim 81 \%$

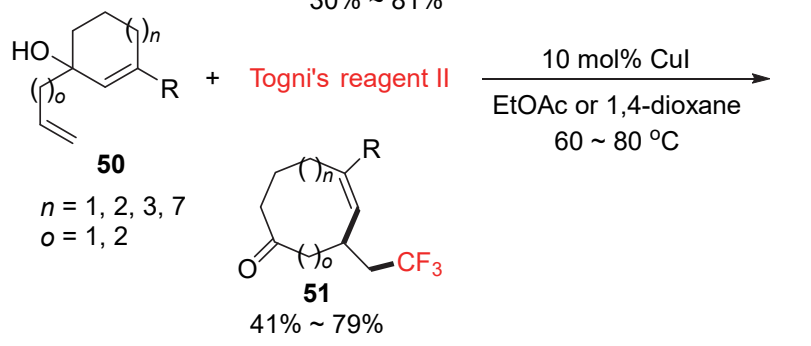

图式 16 铜催化的三氟甲基自由基促进的烯基迁移反应

Scheme 16 Trifluoromethyl radical promoted alkenyl migration catalyzed by copper

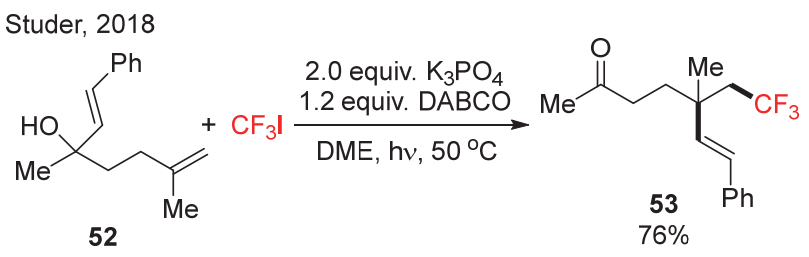

图式 17 无金属参与的烯基迁移反应

Scheme 17 Metal-free catalyzed alkenyl migration
发生单电子转移生成三氟甲基自由基和四价的金属依; 随后，三氟甲基自由基进攻 54 中的双键形成碳自由基 中间体 56, 进一步进攻参键, 生成烯基自由基中间体 57; 57 经过重排发生碳碳键断裂, 生成新的自由基物种 58; 最后 58 进一步被四价的金属铱单电子还原生成碳 正离子 59 和三价铱; 59 经过脱质子化得到最终的产物 55. 深入地对不同链长的烯炔化合物 60 进行研究，探讨 炔基的迁移能力：1,2-, 1,3-及 1,6-炔基迁移在标准条件 下是不能发生的；1,4-和 1,5-炔基迁移可以在标准条件 下顺得进行.

同年, Studer 课题组 ${ }^{[43]}$ 在研究全氟烷基自由基促进 的炔基迁移反应的同时，将体系扩展到三氟甲基体系 (Scheme 19). 使用三氟磑甲烷作为三氟甲基自由基源, 在无金属条件下，通过炔基的 1,4-迁移，实现了非活化 烯烃的三氟甲基/炔基化反应，以 $41 \%$ 的收率得到了化 合物 62. 2019 年, 朱晨课题组 ${ }^{[44]}$ 进一步对三氟甲基自由 基引发的炔基迁移反应进行了研究. 使用廉价易得的三 氟甲基试剂三氟甲磺酰氯代替 Umemoto 试剂, 以中等 产率得到相应的双官能团化产物 $\mathbf{5 5}$.

\section{5 其它基团的迁移}

2016 年, 刘心元课题组 ${ }^{[45]}$ 通过三氟甲基自由基促 进的远程 1,4-和 1,5-氯基迁移实现了非活化烯烃的三氟 甲基-氧基双官能团化(Scheme 20). 该反应在金属铜的 催化作用下进行, 使用 Togni's reagent II 试剂作为三氟

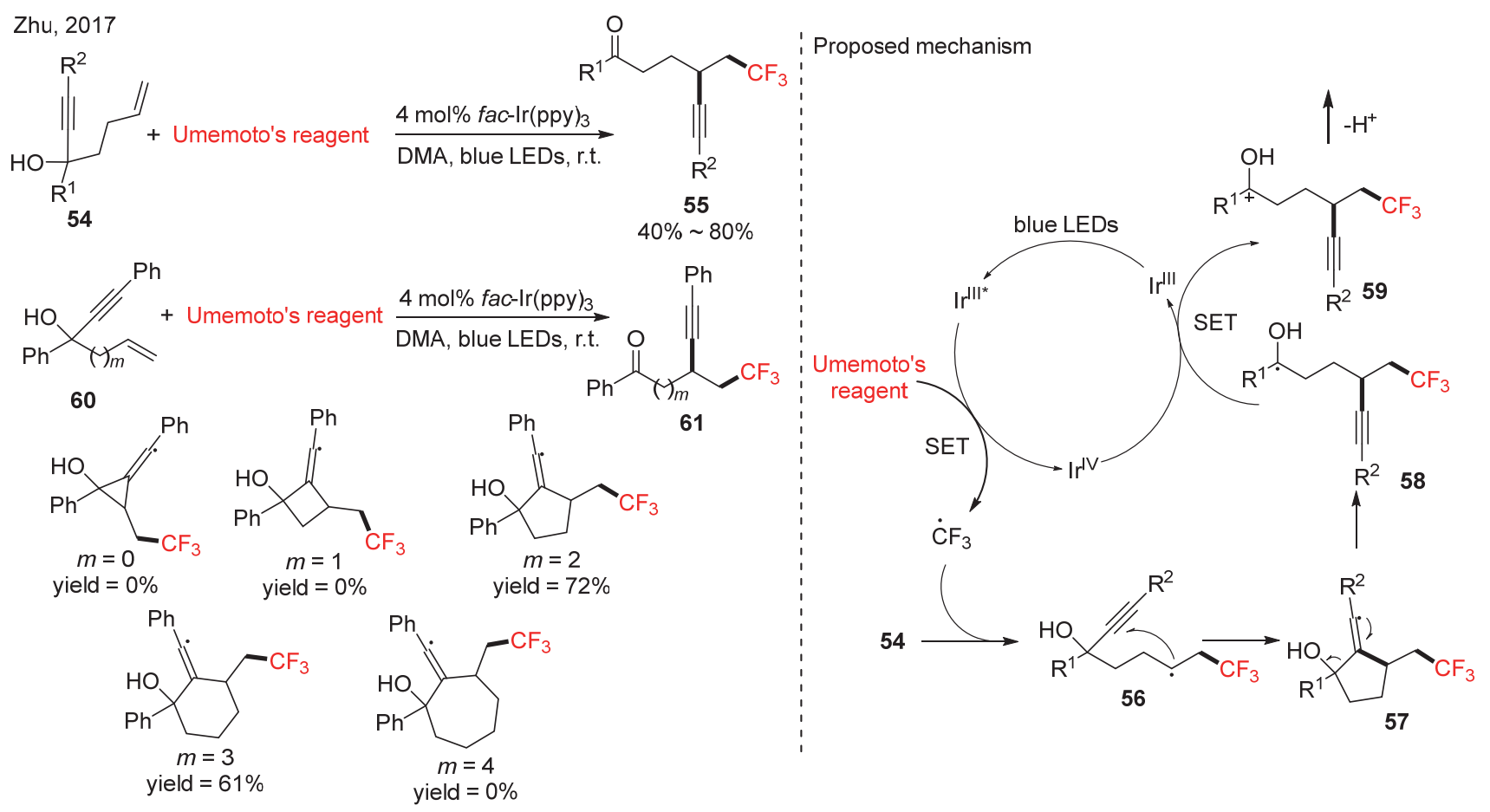

图式 18 光催化的三氟甲基自由基促进的炔基迁移反应

Scheme18 Photocatalytic trifluoromethyl radical promoted alkynyl migration 

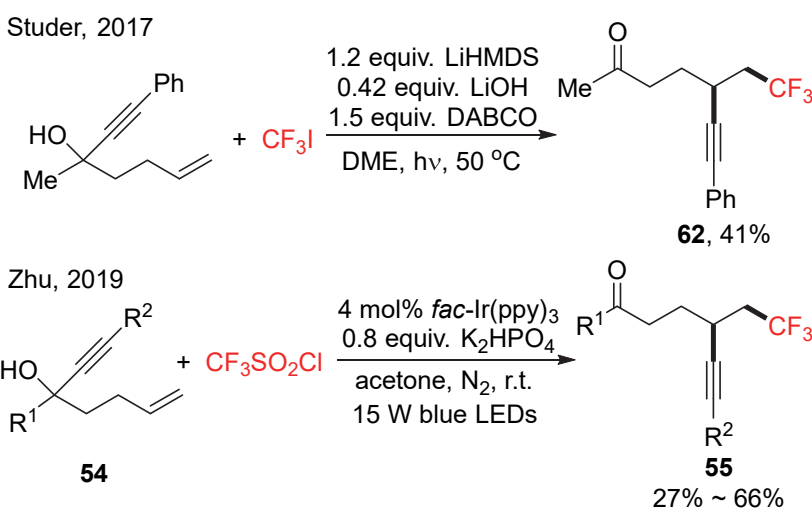

图式 19 三氟甲基自由基促进的炔基迁移反应

Scheme19 Trifluoromethyl radical promoted alkynyl migration

Liu, 2016

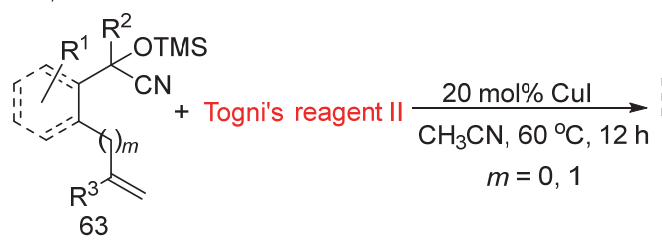<smiles></smiles>

+ Togni's reagent II $\frac{20 \mathrm{~mol} \% \mathrm{Cul}}{\mathrm{CH}_{3} \mathrm{CN}, 60^{\circ} \mathrm{C}, 12 \mathrm{~h}}$

65<smiles>N#CC(CCC(=O)c1ccccc1)CC(F)(F)F</smiles>

图式 20 三氟甲基自由基促进的氰基迁移反应

Scheme 20 Trifluoromethyl radical promote cyano migration
甲基自由基源，硅醚保护的醇 63 为原料，高产率、高区 域选择性地得到了一系列的多官能团化化合物 64. 未 被保护的醇 65 在标准条件下与 Togni's reagent II 试剂反 应，也能以良好的产率得到 1,4-氰基迁移的产物.

除了氭基外，醛基和羰基都能发生迁移反应. 刘心 元课题组 ${ }^{[46]}$ 对这方面进行了深入的研究, 通过三氟甲 基自由基引发, 分别高效率地实现了醛基的 1,2-迁移、 1,4-迁移和 1,5-迁移，得到了各种 $\beta$-三氟甲基化的醛类 化合物 67 (Scheme 21). 此外, 使用三氟甲磺酰氯作为 三氟甲基自由基前体，也可以在光催化条件下得到相应 的 1,4-醛基迁移产物. 进一步扩展反应体系到环酮类化 合物 68, 在铜的催化下, 与 Togni's reagent II 试剂反应, 发生 1,5-羰基迁移，得到十元环类化合物 69.

在铜催化下, 肜类化合物 $\mathbf{7 0}$ 与 Togni's reagent II 试 剂反应生成 $\beta$-三氟甲基取代的肜类化合物 71 (Scheme $22)^{[47]}$. 在该反应中肟基团发生了迁移，其反应机理如 下: 首先 Togni's reagent II 试剂与一价铜发生单电子转 移生成三氟甲基自由基和二价铜物种，三氟甲基自由基 进攻双键得到碳自由基中间体 72; 碳自由基中心进攻 肜基生成氮自由基物种 73, 随后发生重排开环，得到自 由基中间体 74; 74 与二价铜物种进一步发生单电子还 原，并脱掉一个质子得到非活化烯烃的三氟甲基化/肜 化产物 71. 当使用环肜类化合物 75 为底物时, 同样可 以发生三氟甲基自由基促进的迁移反应，生成八到十元 环肜类化合物 76. 此外二氟烷基自由基和全氟烷基自 由基也可以促进这类迁移反应的发生.

Liu, 2016

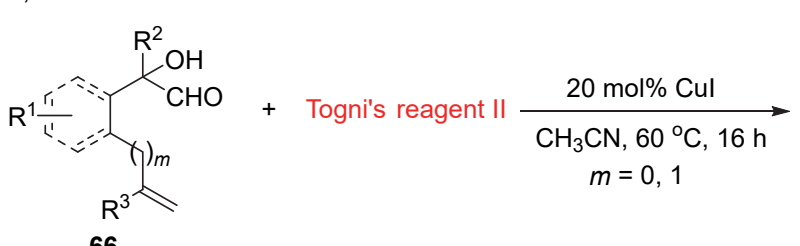

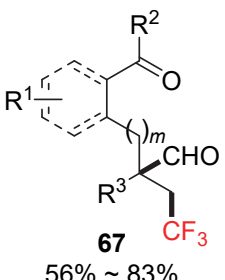

66 $56 \% \sim 83 \%$<smiles>O=CCCC(O)(c1ccccc1)c1ccccc1</smiles>

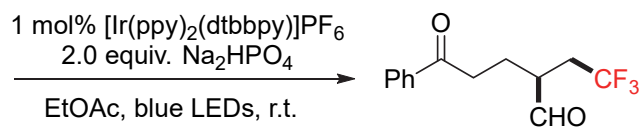
EtOAc, blue LEDs, r.t. $71 \%$<smiles>C=CCc1ccccc1C1(O)CCCCC1=O</smiles>

图式 21 三氟甲基自由基促进的醛基、羰基迁移反应

Scheme 21 Trifluoromethyl radical promoted aldehyde and carbonyl group migration 


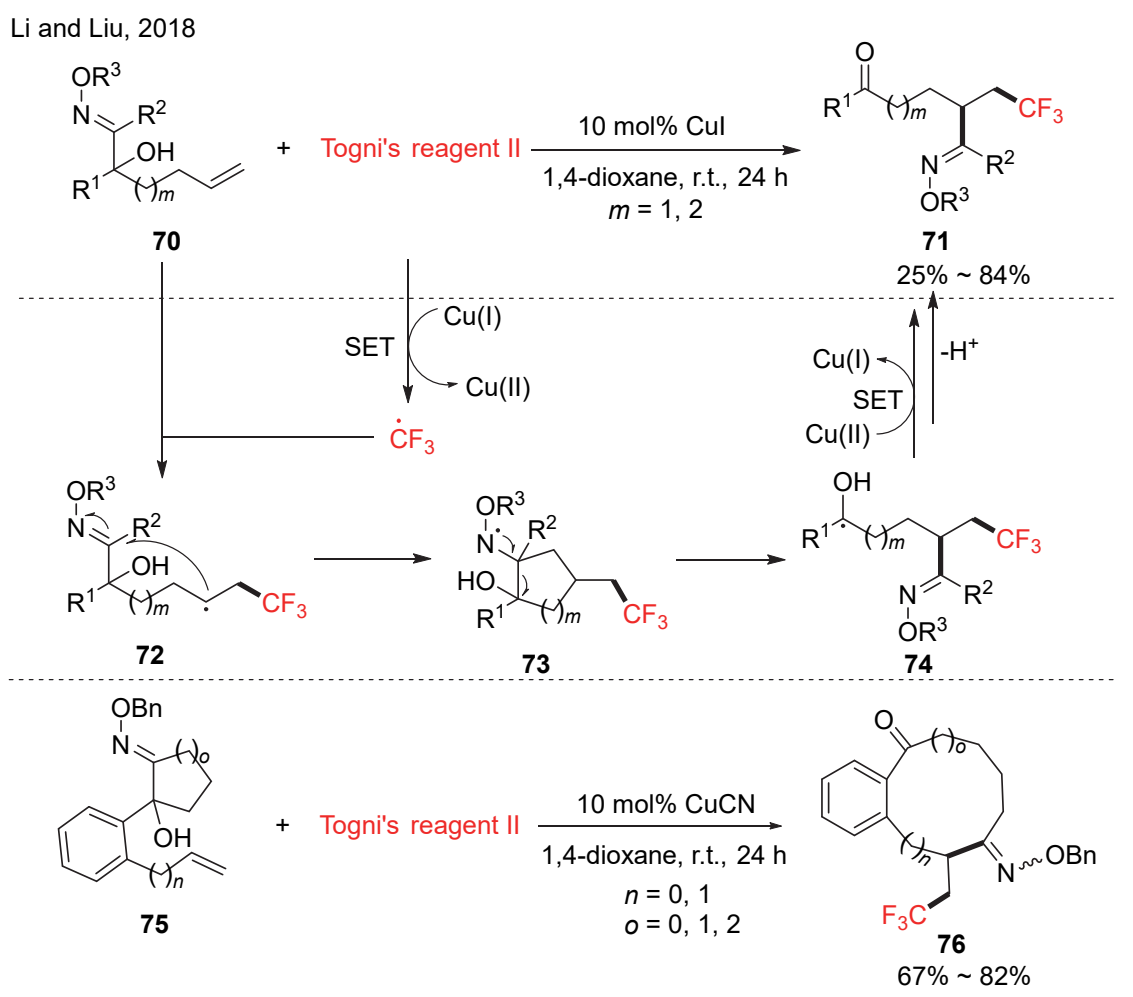

图式 22 三氟甲基自由基促进肜的远程迁移反应

Scheme 22 Trifluoromethyl radical promote remote oximino migration

\section{3 总结和展望}

对当前发展的通过三氟甲基自由基促进的迁移策 略实现烯烃双官能团化的方法进行了分类总结, 这对于 活化烯烃和非活化烯烃的三氟甲基化/官能团化有着重 要的意义. 这些自由基反应大多反应条件温和, 底物的 兼容性广泛, 并且通过分子内的迁移策略实现烯烃的双 官能团化大大提高了反应的原子经济性, 具有重要的合 成价值和研究意义.

近年来, 三氟甲基自由基促进的迁移反应取得了重 大的进展, 发展了许多新的迁移类型. 然而现阶段的发 展仍然存在一定的局限性, 需要进一步的改良与发展, 主要概括为以下几个方面: (1)发展更加温和、无过渡金 属参与的催化体系更符合绿色化学发展的要求; (2)现已 发展的方法中使用的三氟甲基源主要为 Togni 试剂和 Umemoto 试剂, 虽然已经商业化, 但是其价格仍然偏 高, 发展更廉价的三氟甲基自由基前体对于降低反应的 成本有着重要的意义; (3)迁移的对映选择性, 如何更好 地利用迁移的空间位阻来实现不对称中心的构建, 需要 化学工作者进一步的努力; (4)进一步完善迁移模式, 发 展更多新型的迁移反应，对于扩大这一类反应的应用有 着重要的意义.

\section{References}

[1] (a) Harvey, D. F.; Sigano, D. M. Chem. Rev. 1996, 96, 271. (b) Grubbs, R. H.; Chang, S. Tetrahedron 1998, 54, 4413.

(c) Baird, M. C. Chem. Rev. 2000, 100, 1471.

(d) Takacs, J. M.; Jiang, X.-T. Curr. Org. Chem. 2003, 7, 369.

(e) Prunet, J. Angew. Chem., Int. Ed. 2003, 42, 2826.

(f) Beller, M.; Seayad, J.; Tillack, A.; Jiao, H. Angew. Chem., Int. Ed. 2004, 43, 3368.

(g) Chirik, P. J. Acc. Chem. Res. 2015, 48, 1687.

[2] (a) Lan, X.; Wang, N.; Xing, Y. Eur. J. Org. Chem. 2017, 5812.

(b) Liu, G.; Shannon, S. S. Chem. Rev. 2011, 111, 2981.

(c) Smidt, J.; Hafner, W.; Jira, R.; Sedlmeier, J.; Sieber, R.; Kojer, H. Angew. Chem. 1959, 71, 176.

(d) Smidt, J.; Hafner, W.; Jira, R.; Sieber, R.; Sedlmeier, J.; Sabel, A. Angew. Chem., Int. Ed. 1962, 1, 80.

(e) Jira, R. Angew. Chem., Int. Ed. 2009, 48, 9034.

[3] (a) Filler, R.; Kobayashi, Y.; Yagupolskii, L. M. Organofluorine Compounds in Medicinal Chemistry and Biomedical Applications, Elsevier, Amsterdam, 1993.

(b) Schlosser, M. Angew. Chem., Int. Ed. 2006, 45, 5432.

(c) Muller, K.; Faeh, C.; Diederich, F. Science 2007, 317, 1881.

[4] (a) Kellner, R.; Bruzzese, D.; Winslow, W. W.; Rada, R. T.; Wall, F. J. Clin. Pharmacol. 1978, 18, 20.

(b) Fann, W. E.; Sullivan, J. L.; Miller, R. D. Curr. Ther. Res.1974, 16, 1281.

(c) Fann, W. E.; Richman, B. W.; Pitts, W. M. Curr. Ther. Res. 1982, 32, 906.

[5] (a) Freston, J. W.; Pilmer, B. L.; Chiu, Y. L.; Wang, Q.; Stolle, J. C.; Griffin, J. S.; Lee, C. Q. Aliment. Pharmacol. Ther. 2004, 19, 1111. (b) Miura, M.; Tada, H.; Yasui-Furukori, N.; Uno, T.; Sugawara, K.; Tateishi, T.; Suzuki, T. Eur. J. Clin. Pharmacol. 2004, 60, 623.

(c) Sachs, G.; Shin, J. M.; Howden, C. W. Aliment. Pharmacol. Ther. 2006, 23, 2 . 
(d) Zimmermann, A. E.; Katona, B. G. Pharmacotherapy 1997, 17, 308.

[6] (a) Tanaka, Y.; DeLuca, H. F.; Kobayashi, Y.; Ikekawa, N. Arch. Biochem. Biophys. 1984, 229, 348.

(b) Morii, H.; Ogura, Y.; Koshikawa, S.; Mimura, N.; Suzuki, M.; Kurokawa, K.; Marumo, F.; Kawaguchi, Y.; Maeda, K.; Nishizawa, Y.; Inoue, S.; Fujimi, S.; Falecalcitriol Phase Secondary Hyperparathyroidism Treatment Study Group III. J. Bone Miner. Metab. 1998, 16, 34.

(c) Akiba, T.; Marumo, F.; Owada, A.; Kurihara, S.; Inoue, A.; Chida, Y.; Ando, R.; Shinoda, T.; Ishida, Y.; Ohashi, Y. Am. J. Kidney Dis. 1998, 32, 238.

(d) Durakovic, C.; Malabanan, A.; Holick, M. F. Br. J. Dermatol. 2001, 144, 500 .

[7] (a) Delbarre, B.; Dumas, G. Experientia 1969, 25, 850.

(b) Prasad, T. N. V.; Rao, E. V.; Sastry, B. S.; Sastry, C. S. P.; Kostek, L. J. Anal. Profiles Drug Subst. 1991, 20, 665.

[8] (a) Bhatt, D. L.; Lincoff, A. M.; Gibson, C. M.; Stone, G. W.; McNulty, S.; Montalescot, G.; Kleiman, N. S.; Goodman, S. G.; White, H. D.; Mahaffey, K. W.; C. V. Pollack, Jr. C. V.; Manoukian, S. V.; Widimsky, P.; Chew, D. P.; Cura, F.; Manukov, I.; Tousek, F.; Jafar, M. Z.; Arneja, J.; Skerjanec, S.; Harrington, R. A. N. Engl. J. Med. 2009, 361, 2330 .

(b) Harrington, R. A.; Stone, G. W.; McNulty, S.; White, H. D.; Lincoff, A. M.; Gibson, C. M.; Pollack, Jr. C. V.; Montalescot, G.; Mahaffey, K. W.; Kleiman, N. S.; Goodman, S. G.; Amine, M.; Angiolillo, D. J.; Becker, R. C.; Chew, D. P.; French, W. J.; Leisch, F.; Parikh, K. H.; Skerjanec, S.; Bhatt, D. L. N. Engl. J. Med. 2009, 361, 2318.

(c) Kastrati, A.; Ndrepepa, G. N. Engl. J. Med. 2009, 361, 2382.

(d) Angiolillo, D. J.; Schneider, D. J.; Bhatt, D. L.; French, W. J.; Price, M. J.; Saucedo, J. F.; Shaburishvili, T.; Huber, K.; Prats, J.; Liu, T.; Harrington, R. A.; Becker, R. C. J. Thromb. Thrombolysis 2012, 34, 44 .

(e) Leonardi, S.; Mahaffey, K. W.; White, H. D.; Gibson, C. M.; Ston, G. W.; Steg, G. W.; Hamm, C. W.; Price, M. J.; Todd, M.; Dietrich, M.; Gallup, D.; Liu, T.; Skerjanec, S.; Harrington, R. A.; Bhatt, D. L. Am. Heart J. 2012, 163, 768.

[9] (a) Wang, X.; Zhang, Y.; Wang, J. Sci. Sin.: Chim. 2012, 42, 1417 (in Chinese).

(王兮，张艳，王剑波，中国科学：化学, 2012, 42, 1417.)

(b) Zeng, W.; Chen, F. Chin. J. Appl. Chem. 2014, 31, 627 (in Chinese).

(曾薇, 陈甫雪, 应用化学, 2014, 31, 627.)

(c) Li, M.; Kang, H.; Xue, X.-S.; Cheng, J.-P. Acta Chim. Sinica 2018, 76, 988 (in Chinese).

(李曼, 康会英, 薛小松, 程津培, 化学学报, 2018, 76, 988.)

(d) Ji, X.; Shi, G.; Zhang, Y. Chin. J. Org. Chem. 2019, 39, 929 (in Chinese).

(季小明, 史广法, 张扬会, 有机化学, 2019, 39, 929.)

[10] (a) Chen, Z.-M.; Zhang, X.-M.; Tu, Y.-Q. Chem. Soc. Rev. 2015, 44,5220 .

(b) Li, W.; Xu, W.; Xie, J.; Yu, S.; Zhu, C. Chem. Soc. Rev. 2018, 47, 654 .

(c) Wu, X.; Wu, S.; Zhu, C. Tetrahedron Lett. 2018, 59, 1328

(d) Zhang, G.; Liu, Y.; Zhao, J.; Li, Y.; Zhang, Q. Sci. China: Chem. 2019, 62, 1476.

(e) Wu, X.; Zhu, C. Acc. Chem. Res. 2020, 53, 1620.

(f) Chen, D.; Ji, M.; Yao, Y.; Zhu, C. Acta Chim. Sinica 2018, 76, 951 (in Chinese).

(陈栋，吉梅山，姚英明，朱晨，化学学报, 2018, 76, 951.)

[11] (a) Liu, X.; Xiong, F.; Huang, X.; Xu, L.; Li, P.; Wu, X. Angew. Chem., Int. Ed. 2013, 52, 6962.

(b) Liu, X.; Wu, X. Synlett 2013, 24, 1882

[12] Chen, Z.-M.; Bai, W.; Wang, S.-H.; Yang, B.-M.; Tu, Y.-Q.; Zhang, F.-M. Angew. Chem., Int. Ed. 2013, 52, 9781.

[13] Egami, H.; Shimizu, R.; Usui, Y.; Sodeoka, M. Chem. Commun. 2013, 49, 7346
[14] Xu, P.; Hu, K.; Gu, Z.; Cheng, Y.; Zhu, C. Chem. Commun. 2015, 51,7222 .

[15] Huang, H.-L.; Yan, H.; Gao, G.-L.; Yang, C.; Xia, W. Asian J. Org. Chem. 2015, 4, 674.

[16] Cai, S.; Tian, Y.; Zhang, J.; Liu, Z.; Lu, M.; Weng, W.; Huang, M. Adv. Synth. Catal. 2018, 360, 4084.

[17] Wang, H.; Xu, Q.; Yu, S. Org. Chem. Front. 2018, 5, 2224.

[18] Guan, Z.; Wang, H.; Huang, Y.; Wang, Y.; Wang, S.; Lei, A. Org. Lett. 2019, 21, 4619.

[19] Natho, P.; Allen, L. A. T.; Parsons, P. J. Tetrahedron Lett. 2020, 61 , 151695

[20] Sahoo, B.; Li, J.-L.; Glorius, F. Angew. Chem., Int. Ed. 2015, 54, 11577.

[21] Woo, S. B.; Kim, D. Y. J. Fluorine Chem. 2015, 178, 214.

[22] Kang, J.-C.; Tu, Y.-Q.; Dong, J.-W.; Chen, C.; Zhou, J.; Ding, T.-M.; Zai, J.-T.; Chen, Z.-M.; Zhang, S.-Y. Org. Lett. 2019, 21, 2536.

[23] Jung, H. I.; Kim, Y.; Kim, D. Y. Org. Biomol. Chem. 2019, 17, 3319.

[24] Li, M.; Zhu, X.-Y.; Qiu, Y.-F.; Han, Y.-P.; Xia, Y.; Wang, C.-T.; Li, X.-S.; Wei, W.-X.; Liang, Y.-M. Adv. Synth. Catal. 2019, 361, 2945.

[25] Kong, W.; Casimiro, M.; Merino, E.; Nevado, C. J. Am. Chem. Soc. 2013, 135, 14480 .

[26] Fuentes, N.; Kong, W.; Fernóndez-Sónchez, L.; Merino, E.; Nevado, C. J. Am. Chem. Soc. 2015, 137, 964.

[27] Kong, W.; Fuentes, N.; García-Domínguez, A.; Merino, E.; Nevado, C. Angew. Chem., Int. Ed. 2015, 54, 2487.

[28] Yu, P.; Lin, J.-S.; Li, L.; Zheng, S.-C.; Xiong, Y.-P.; Zhao, L.-J.; Tan, B.; Liu, X.-Y. Angew. Chem., Int. Ed. 2014, 53, 11890.

[29] Yu, P.; Zheng, S.-C.; Yang, N.-Y.; Tan, B.; Liu, X.-Y. Angew. Chem., Int. Ed. 2015, 54, 4041.

[30] Huang, L.; Lin, J.-S.; Tan, B.; Liu, X.-Y. ACS Catal. 2015, 5, 2826.

[31] Huang, L.; Zheng, S.-C.; Tan, B.; Liu, X.-Y. Org. Lett. 2015, 17, 1589.

[32] Huang, L.; Zheng, S.-C.; Tan, B.; Liu, X.-Y. Chem.-Eur. J. 2015 21,6718 .

[33] Cheng, C.; Liu, S.; Lu, D.; Zhu, G. Org. Lett. 2016, 18, 2852.

[34] Lonca, G. H.; Ong, D. Y.; Tran, T. M. H.; Tejo, C.; Chiba, S.; Gagosz, F. Angew. Chem., Int. Ed. 2017, 56, 11440.

[35] Chen, Z.-M.; Zhang, X.-M.; Tu, Y.-Q. Chem. Soc. Rev. 2015, 44, 5220 .

[36] Li, L.; Li, Z.-L.; Wang, F.-L.; Guo, Z.; Cheng, Y.-F.; Wang, N.; Dong, X.-W.; Fang, C.; Liu, J.; Hou, C.; Tan, B.; Liu, X.-Y. Nat. Commun. 2016, 7, 13852.

[37] Li, L.; Gu, Q.-S.; Wang, N.; Song, P.; Li, Z.-L.; Li, X.-H.; Wang, F.-L.; Liu, X.-Y. Chem. Commun. 2017, 53, 4038.

[38] Wu, Z.; Wang, D.; Liu, Y.; Huan, L.; Zhu, C. J. Am. Chem. Soc. 2017, 139, 1388

[39] Jeon, J.; He, Y.-T.; Shin, S.; Hong, S. Angew. Chem., Int. Ed. 2020, $59,281$.

[40] Li, L.; Li, Z.-L.; Gu, Q.-S.; Wang, N.; Liu, X.-Y. Sci. Adv. 2017, 3, e1701487.

[41] Tang, X.; Studer, A. Angew. Chem., Int. Ed. 2018, 57, 814.

[42] Xu, Y.; Wu, Z.; Jiang, J.; Ke, Z.; Zhu, C. Angew. Chem., Int. Ed. 2017, 56, 4545 .

[43] Tang, X.; Studer, A. Chem. Sci. 2017, 8, 6888.

[44] Tang, N.; Shao, X.; Wang, M.; Wu, X.; Zhu, C. Acta Chim. Sinica 2019, 77, 922 (in Chinese). (汤娜娜，邵金金，王明扬，吴新金金，朱晨，化学学报，2019，77, 922.)

[45] Wang, N.; Li, L.; Li, Z.-L.; Yang, N.-Y.; Guo, Z.; Zhang, H.-X.; Liu, X.-Y. Org. Lett. 2016, 18, 6026.

[46] Li, Z.-L.; Li, X.-H.; Wang, N.; Yang, N.-Y.; Liu, X.-Y. Angew. Chem., Int. Ed. 2016, 55, 15100 .

Wang, N.; Wang, J.; Guo, Y.-L.; Li, L.; Sun, Y.; Li, Z.; Zhang, H.-X.; Guo, Z.; Li, Z.-L.; Liu, X.-Y. Chem. Commun. 2018, 54, 8885.

(Zhao, C.) 